\title{
PENERAPAN PRINSIP AKUNTABILITAS Pada BUMDes TEJA KUSUMA
}

\author{
Kadek Rindi, Luh Putu Mas Sintia Arsani Dewi, Dyah Ari Puspita Sari, \\ Putu Pania Awitiana \\ Jurusan Akuntansi, Universitas Pendidikan Ganesha, Singaraja, Bali, Indonesia
}

\begin{abstract}
Abstrak
Penelitian ini bertujuan untuk mengetahui Kendala yang terjadi dalam mendirikan BUMDes, Fasilitas apa saja yang diberikan BUMDes, apa tujuan pendirian BUMDes, dampak yang diberikan dari dibentuknya BUMDes dalam bidang sosial ekonomi, apakah BUMDes sudah berjalan efektif di desa, bagaimana tata kelola BUMDes di desa tersebut, Bagaimana prinsip akuntabilitas yang diterapkan dalam BUMDes. Penelitian ini merupakan penelitian kualitatif. Data penelitian ini diperoleh dari wawancara kepada Kadek Darwita selaku Ketua BUMDes Teja Kusuma, karena dianggap mengetahui dan dapat memberikan informasi mengenai seluk-beluk tentang kegiatan BUMDes Teja Kusuma. Dalam BUMDes Teja Kusuma ini segala bentuk pengambilan keputusannya menggunakan sistem Demokrasi.Disini selaku pengurus, pengawas, beserta penanggung jawab BUMDes memiliki jumah suara sebanyak 2, dan pegawai BUMDes memiliki jumlah suara 1. Hal yang dibahasa adalah tentang pelaporan pertanggung jawaban oleh seluruh pengurus BUMDes yang melibatkan tokohtokoh penting desa, beserta beberapa wakil dari masyarakat di desa Tejakula. Jadi dapat dikatakan bahwa BUMDes Teja Kusuma ini sudah menerapkan prinsip akuntabilitas atau pertanggung jawaban terhadap segala aspek kegiatan yang terjadi di dalam pelaksanaan kegiatan operasional, baik secara internal maupun eksternal.
\end{abstract}

Kata kunci: Akuntabilitas; BUMDes; Desa

\begin{abstract}
This study aims to determine the obstacles that occur in establishing BUMDes, what facilities are provided by BUMDes, what are the objectives of establishing BUMDes, the impact given from the establishment of BUMDes in the socio-economic field, whether BUMDes has been effective in the village, how is the governance of BUMDes in the village, How is the principle of accountability applied in BUMDes. This research is a qualitative research. The data of this study were obtained from interviews with Kadek Darwita as Chairman of the BUMDes Teja Kusuma, because they were considered to know and could provide information about the intricacies about BUMDes Teja Kusuma's activities. In BUMDes Teja Kusuma all forms of decision making use the Democracy system. Here as the management, supervisor, and person in charge of BUMDes has 2 votes, and BUMDes employees have a number of votes 1 . The matter discussed is about reporting responsibility by all BUMDes management who involving important village figures, along with several representatives from the community in Tejakula village. So it can be said that BUMDes Teja Kusuma has applied the principle of accountability or accountability to all aspects of activities that occur in the implementation of operational activities, both internally and externally..
\end{abstract}

Keywords: Accountability; BUMDes; Village

\section{Pendahuluan}

Menurut Undang Undang Nomor 5 Tahun 1979 menyatakan bahwa "Desa adalah suatu wilayah yang ditempati oleh sejumlah penduduk sebagai kesatuan masyarakat termasuk didalamnya kesatuan masyarakat hukum yang mempunyai organisasi pemerintahan terendah langsung dibawah camat dan berhak menyelenggarakan rumah tangganya sendiri dalam ikatan kesatuan Republik Indonesia.

Dalam pengertian tersebut,di dalam lingkup desa perlu terdapat sumber-sumber pendanaan desa seperti pendapatan asli desa,pendapatan asli desa ini berasal dari usaha hasil BUMdes,hasil tanah kas desa,pembagian laba yang berasal dari perusahaan negara ataupun swasta.

Dalam penelitian ini,akan dibahas mengenai pendanaan desa yang berasal dari usaha BUMdes. Dimana usaha ini hampir diterapkan di semua desa, karena BUMdes ini 
sangat memiliki manfaat yang besar bagi pendanaan desa. Dalam mencari sumber pendanaan, pemerintah desa memiliki tujuan untuk meningkatkan pembangunan agar lebih baik.

Dalam UU No. 6 tahun 2014 dijelaskan bahwa BUMdes merupakan badan usaha yang seluruh atau sebagian modalnya dimiliki oleh desa melalui penyertaan secara langsung yang berasal dari kekayaan desa yang dipisahkan guna mengelola aset,jasa pelayanan,dan usaha lainya untuk sebesar-besarnya kesejahteraan masyarakat desa.

Sedangkan menurut Pasal 107 ayat (1) huruf (a) Undang-Undang Nomor 22 Tahun 1999 dinyatakan bahwa sumber pendapatan Desa salah satunya adalah pendapatan asli desa, yang meliputi:

1. Hasil usaha desa.

2. Hasil swadaya dan partisipasi.

3. Hasil gotong royong.

4. Lain-lain pendapatan asli desa yang sah.

Penjelasan Pasal 107 ayat (1) menyebutkan bahwa pemberdayaan potensi desa dalam meningkatkan pendapatan desa dilakukan, antara lain, dengan pendirian Badan Usaha Milik Desa, kerja sama dengan pihak ketiga, dan kewenangan melakukan pinjaman.

Usaha BUMdes ini tidak hanya fokus dalam pengelolaan dana simpan pinjam,namun juga mengajak masyarakat untuk bisa memanfaatkan barang yang tidak berguna enjadi berguna. Misalnya seperti pengelolahaan sampah menjadi rupiah,rupaih dalam hal ini menjadi barang-barang yang lebih bermanfaat,selain mendapatkan nilai ekonomis dari kegiatan tersebut,juga dapat mengurangi risiko banjir,polusi di desa. Permasalahan utama dalam pengelolaan dana desa salah satunya kemampuan pendamping dana desa yang justru belum paham bagimana mengelola dana. Dalam hal ini aparat desa harus mampu mempertanggungjawabkan tata kelola desa dengan baik dan mampu menciptakan transparansi.

BUMDes ini sangat penting karena dasarnya merupakan pilar kegiatan ekonomi di desa yang berfungsi sebagai lembaga sosial dan komersial. BUMDes ini sebagai lembaga sosail harusnya berpihak kepada kepentingan masyarakat melalui kontribusinya dalam penyediaan pelayanan sosial.

Akuntabilitas merupakan istilah yang digunakan untuk menggambarkan tingkat pertanggungjawaban seseorang ataupun suatu lembaga tertentu yang berkaitan dengan sistem administrasi yang dimilikinya.Menurut Mardiosmo, akuntabilitas adalah sebuah kewajiban melaporkan dan bertanggungjawab atas keberhasilan ataupun kegegalan pelaksanaan misi organisasi dalam mencapai hasil yang telah ditetapkan sebelumnya,melalui media pertanggungjawaban yang dikerjakan secara berkala.

Dalam penelitian ini akan dijelaskan khusus tentang prinsip akuntanbilitas dalam usaha BUMDes. Dalam penerapannya,aparat desa akan memberikan pertanggungjawaban yang apa adanya.Tercapainya akuntabilitas di tingkat desa, merupakan pintu masuk bagi pemerintah desa dalam memberikan informasi pada masyarakat. Baik yang berkaitan dengan pengelolaan keuangan desa ataupun informasi berkaitan dengan kebijakan yang diambil oleh pemerintah desa. Hal ini dikarenakan masyarakat mempunyai hak untuk mendapatkan informasi dalam melakukan pengawasan terhadap kinerja pemerintah desa.

Berdasarkan permasalahan diatas, adapun rumusan masalah yang dilakukan yaitu Kendala yang terjadi dalam mendirikan BUMDes, Fasilitas apa saja yang diberikan BUMDes, Apa tujuan pendirian BUMDes, Dampak yang diberikan dari dibentuknya BUMDes dalam bidang sosial ekonomi, Apakah BUMDes sudah berjalan efektif di desa, Bagaimana tata kelola BUMDes di desa tersebut, Bagaimana prinsip akuntabilitas yang diterapkan dalam BUMDes.

\section{Metode}

\section{Metode Pengumpulan Data}

Penelitian ini merupakan penelitian kualitatif. Penelitian kualitatif merupakan penelitian yang digunakan untuk menghasilkan data deskriptif yang ditulis atau diucapkan orang dan perilaku-perilaku yang dapat diamati (Bigdan dan Taylor, 1975; Pawito, 2018). 
Metode analisis deskriptif bertujuan untuk mendeskripsikan secara sistematis, faktual, dan akurat mengenai fakta, sifat, serta hubungan antar fenomena yang diteliti (Nawawi, 1998). Menurut Husaini dan Purnomo (2009:130) bahwa penelitian deskriptif kualitatif adalah menguraikan pendapat responden apa adanya sesuai dengan pertanyaan penelitian, kemudian dianalisis dengan katakata yang melatarbelakangi responden berperilaku seperti itu, direduksi, ditriangulasi, disimpulkan, dan diverifikasi.

\section{Lokasi Penelitian}

Lokasi penelitian merupakan daerah atau tempat yang digunakan untuk melaksanakan kegiatan penelitian dan memperoleh data yang diperlukan dalam penyelesaian suatu penelitian. Lokasi penelitian ini dilaksanakan di BUMDes Teja Kusuma yang terletak di Desa Tejakula Kecamatan Tejakula Kabupaten Buleleng.

\section{Jenis dan Sumber Data}

1. Wawancara

Wawancara digunakan sebagai teknik pengumpulan data apabila penelitian ingin melakukan study pendahuluan untuk menemukan masalah yang harus diteliti dan juga apabila peneliti ingin mengetahui hal-hal dari responden yang lebih mendalam dan jumlah respondennya sedikit atau kecil (Sugiono, 2013). Informan atau responden yang dimintai informasi adalah Kadek Darwita selaku Ketua BUMDes Teja Kusuma, karena dianggap mengetahui dan dapat memberikan informasi mengenai seluk-beluk tentang kegiatan BUMDes Teja Kusuma.

2. Teknik Dokumentasi

Menurut Sugiyono (2013), dokumen merupakan catatan peristiwa yang sudah berlalu yang berbentuk tulisan, gambar, atau karya-karya monumental dari seseorang. Study dokumen merupakan pelengkap dari penggunaan metode wawancara dalam penelitian ini. Dokumen yang digunakan adalah jurnal ilmiah, tulisan atau opini yang bersumber dari jurnal penelitian sebelumnya.

3. Observasi

Pada dasarnya teknik observasi digunakan untuk melihat dan mengamati perubahan fenomena-fenomena social yang tumbuh dan berkembang yang kemudian dapat dilakukan perubahan atas penilaian tersebut, bagi pelaksana observaser untuk melihat obyek moment tertentu, sehingga mampu memisahkan antara yang diperlukan dengan yang tidak diperlukan. (Margono, 2007:159). Dalam penelitian ini kami melakukan observasi ke BUMDes Teja Kusuma untuk melakukan wawancara dan melihat langsung apa saja kegiatan yang dilakukan oleh BUMDes Teja Kusuma.

\section{HasildanPembahasan}

\section{Kendala Dalam Menjalankan Kegiatan BUMdes.}

Berdasarkan penelitian yang kami lakukan di BUMdes "TEJAKUSUMA" yang berada di desa Tejakula, bahwa meneurut Bapak Kadek Darwita yang selaku Ketua BUMdes tersebut menyatakan bahwa kendala-kendala yang ditemukan dalam menjalankan Kegiatan BUMdes tersebut adalah:

1. Sumber Daya Manusia (SDM) yang terbatas.

Sumber Daya Manusia (SDM) merupakan salah satu faktor yang sangat penting bahkan tidak dapat dilepaskan dari sebuah organisasi pemerintahan di Desa. Dalam menjalankan kegiatan BUMdes ini kekurangan Sumber Daya Manusia menjadi salah satu faktor yang mengakibatkan ketidakefektivan kinerja BUMdes dalam melayani masyarakat seperti dalam Unit Pengelolaan Usaha Hutan Desa dan Unit Pengelolaan Sampah. Dalam menjalankan Unit Pengelolaan Usaha Hutan Desa masih sangat kurangnya kesdaran dari masyarakat setempat dalam pengelolaan hutan. Selain itu dalam pengelolaan Sampah ini masih sedikit yang ingin menjadi buruh untuk melekukan kegiatan meilah sampah antara sampah organik dan non organik. Selain itu tidak tersedianya tenaga profesional dalam mengelola sampah tersebut.

2. Keterbatasan Alat. 
Faktor keterbatasan alat yang dimaksud seperti peralatan yang digunakan dalam mengelola atau mengolah sampah organik maupaun non organik. Meskipun untuk sampah organik sudah terdapat alatnya tetapi peralatannya masih kecil sehingga kewalahan dalam mengelola sampahnya karena sampah yang datang terlalu banyak. Begitupun dalam pengelolaan sampah non organik juga masih mengalami keterbatasan alat, karena belum terdapat alat yang dapat mengelola sampah plastik yang tidak memberikan dampak negatif terhadap masyarakat.

\section{Usaha yang diberikan BUMdes.}

Adapun unit usaha simpan pinjam, bumdes menjalankan bisnis uang, yang memenuhi kebutuhan keuangan masyarakat desa dengan bunga yang lebih rendah dari pada bunga uang yang didapatkan dimasyarakat desa dari pada bunga uang yang didapatkan masyarakat desa dari para rentenir desa atau bank bank konversional.bumdes desa menjalankan bisnis penyewaan untuk melayani kebutuhan masyarakat setempat dan sekaligus untuk dapat memperoleh pendapatan desa. Melalui berbagai unit usaha di bumdes teja kusuma yang berada ditejakula berbagai kebutuhan dasar warga desa sudah diwadahi dan dipenuhi terutama untuk meminjam uang untuk masyarakat miskin.anggaran usaha ini dikucurkan langsung oleh pemerintah dan diserahkan langsung pengelolannya kepada masyarakat desa, bumdes tersebut merupakan salah satu langkah pemerintah dalam mengupayakan pemerataan sehingga tidak ada kejenjangan antara perkotaan dan pedesaan yang maju, diharapkan masyarakat maju dan diharapkan untuk masyarakat agar memiliki kemandirian dalam hal memajukan desa. Usaha yang digagas dibidang prekonomian,di bumdes tersebut berhasil mengembangkan usahannya yaitu :

a. Unit usaha jasa pelayanan air minum (jpam).

b. Unit usaha pengelolaan pasar.

c. Unit usaha pelayanan samsat.

d. Unit usaha pembayaran listrik (pln).

e. Unit usaha pengelolaan sampah.

f. Unit usaha simpan pinjam

Adapun ide usaha bumdes yang dikembangkan yaitu sebuah sentralisasi ekonomi desa. Sebagai contoh, pembangunan yang dapat memgakomodasi hasil produktivitas warga desa, dselain itu, sentralisasi ekonomi desa juga dapat mengahsilkan produk unggulan baru dari hasil pengelolaan hasil bumi masyarakat desa dengan memanfaatkan tekonologi tepat guna. Salah satu contoh ;

1. Pengelolaan hasil perkebunan masyarakat desa seperti rambutan, duren sehingga bisa dijual di pasaran dengan kualitas yang baik sehingga di jual di pasar luas.

2. Pengelolaan hasil bumi menjadi produk krajinan keban dari koran serta pengemasannya yang siap dijual.

3. Pengelolaan sampah pengelolaan sampah organik maupun non organik menjadi produk yang lebih bermanfaat dan memiliki nilai ekonomis yang lebih. Seperti pupuk ataupun cacahan plastik yang siap untuk dijadikan daur ulang. Dan bila masyarakat mengumpulkaan sampah dan diambil oleh petugas dengan sistem mencatat per kilo sampah tersebut dengan harga Rp. 1000 dan dicatat di buku tabungan dan saldo setiap bulannya akan dipergunakan untuk pembayaran air.

4. Mengelola lingkungan pengelolaan lingkungan desa yang dapat dikembangkan menjadi desa wisata, yang dapat menghasilkan nilai material yang lebih serta menjadikan contoh yang baik bagi desa lainya.

\section{Tujuan Pendirian BUMdes.}

Setiap BUMdes pasti memiliki tujuan yang mampu menopang pembangunan desanya menjadi lebih baik. Adapun tujuan pendirian BUMdes TEJAKUSUMA tersebut adalah sebagai berikut:

1. Meningkatkan perekonomian desa.

BUMdes sebagai usaha milik desa harus mampu meningkatkan perekonomian milik desa dengan membuka unit-unit desa yang dapat dimanfaatkan oleh masyarakat 
setempat untuk dapat meningkatkan perekonomian desa yang lebih baik guna mencukupi kebutuhan masyarakat. Dalam hal ini BUMdes mampu meningkatkan kemandirian ekonomi desa yaitu dengan mampu menyelesaikan persoalan kebutuhan dasar warganya dengan mendayagunakan dan mengoptimalkan potensi sumber daya ekonomi yang dimiliki desa.

2. Meningkatkan pendapatan asli desa.

Pendapatan asli desa adalah pendapatan yang berasal dari kewenangan desa berdasarkan hak asal usul dan kewenangan skala lokal desa. Dalam hal ini pendapatan asli desa yang berasal dari badan usaha milik desa. Menurut bapak Kadek Darwita "hasil dari pendapatan BUMdes $20 \%$ nya masuk kedalam pendapatan asli desa.

3. Meningkatkan pengolahan potensi desa sesuai kebutuhan masyarakat.

Potensi desa adalah daya, kekuatan, kesanggupan, dan kemampuan yang dimiliki oleh suatu desa yang memunyai kemungkinan untuk dapat dikembangkan dalam rangka meningkatkan kesejahteraan masyarakat. Potensi desa yang dimaksud seperti potensi fisik yang merupakan potensi yang berkaitan dengan sumber daya alam yang ada didesa tersebut berupa lingkungan georafis yang dapat menjadi daya tarik wisatawan untuk datang dan menikamti keindahan alam yang disediakan di desa tersebut.

4. Menjadi tulang punggung pertumbuhan dan pemerataan perekonomian desa.

BUMdes harus mampu menjadi tulang punggung masyarakat dalam memberkan fasilitas kenyamanan dan memenuhi kebutuhan masyarakat agar terciptanya pemerataan perekonomian desa.

\section{Dampak yang diberikan dari dibentuknya BUMDes dalam bidang sosial ekonomi.}

1. Menciptakan jiwa kewirausahaan.

Kewirausahaan telah menjadi suatu disiplin ilmu yang mempelajari tentang nilai, kemampuan dan perilaku seseorang dalam menghadapi tantangan hidup untuk memperoleh peluang dengan berbagai resiko yang mungkin dihadapinya. Bahkan untuk menjadi wirausahawan sukses, memiliki bakat saja tidak cukup, tetapi juga harus memiliki pengetahuan segala aspek usaha yang akan ditekuninya. Tugas dari wirausaha sangat banyak, antara lain tugas mengambil keputusan, kepemimpinan teknis, kepemimpinan organisatoris dan komersial, penyediaan modal dll. Maka dengan adanya BUMdes ini maka dapat membantu mengurangi pengangguran.

2. Mengurangi adanya pengangguran.

Dengan adanya unit usaha dalam BUMdes, otomatis BUMdes tersebut pasti akan memerlukan banyak tenaga kerja manusia untuk dapat mengelola setiap unit usaha yang dijalankan. Sehingga dengan adanya BUMdes tersebut setidaknya dapat mengurangi tingkat pengangguran di desa tersebut.olo0s

3. Berdampak pada kesehatan masyarakat.

BUMdes memiliki sebuah usaha pengelolaan sampah dimana usaha tesebut bertujuan untuk mengurangi sampah yang menumpuk di sekitaran lingkungan masyarakat dengan cara mempekerjakan tenaga manuisa untuk berkeliling di desa pada setiap pagi untuk membeli dan mengambil sampah plastik yang ada pada setiap rumah dengan membayar $1 \mathrm{~kg}$ sampah dengan harga $\mathrm{Rp} 1.600$. Dengan adanya kegiatan ini dapat mendorong inisiatif masyarakat untuk tidak membang sampah plastik sembarangan ataupun ke sungai atau selokan sehingga terciptanya lingkungan yang bersih dan sehat.

4. Mengajarkan kesadaran sejak dini kepada anak-anak untuk tidak membuang sampah sembarangan. Dalam hal ini sangan membantu menumbuhkan kesadaran pada anakanak sejak dini akan pentingnya membuang sampah pada tempatnya.

\section{Keefektifitasan Bumdes}

BUMDes Teja Kusuma sudah berdiri sekitar 5 tahun. BUMDes ini mulai berdiri sejak tahun 2013, namun sistem operasionalnya baru mulai berjalan dengan lancar sejak Januari 2014. BUMDes Teja Kusuma ini tidak hanya mementingkan pada hasil yang diperolehnya, 
melainkan juga mementingkan bagaimana untuk lebih meningkatkan kemampuan sumber daya manusianya. Dari hasil wawancara dapat ditarik kesimpulan bahwa BUMDes Teja Kusuma sudah menjalankan perannya sebagai pengembang potensi masyarakat. Sebagai contohnya adalah BUMDes Teja Kusuma memberikan kredit dengan bunga kecil, yaitu hanya $1 \%$ dan tanpa anggunan. Selain itu juga masyarakat diperbolehkan membayar segala jenis transaksinya mulai dari menabung, membayar air, dan membayarkan kreditnya dengan cara menukarnya dengan sampah atau limbah plastik yang nantinya akan ditimbang dan hasilnya akan digunakan oleh masyarakat untuk membayar segala jenis transaksinya. BUMDes Teja Kusuma ini juga mempunyai peran yang sangat penting dalam pemerdayaan masyarakatnya, hal ini dapat dilihat dari keterlibatan masyarakatnya yang semakin banyak terlibat dalam usaha atau pun pengelolaan BUMDes tersebut, namun memang masih ditemukan beberapa kendala atau masalah-masalah kecil yang terjadi dalam pelaksanaannya. BUMDes Teja Kusuma juga terus berupaya untuk melakukan pelatihan kepada masyarakat di desa Tejakula maupun masyakat umum yang ingin berpartisipasi dalam peningkatan BUMDes Teja Kusuma, melalui pelatihan kewirausahaan ataupun pelatihan dasar ketenagakerjaan yang nantinya akan dipergunakan untuk membantu kelancaran kegiatan operasionlan BUMDes Teja Kusuma. Dapat dikatakan bahwa BUMDes Teja Kusuma ini dalam pengembangan potensi masyarakatnya, dikatakan sudah berjalan secara efektif, walaupun masih ada beberapa hal yang masih perlu ditingkatkan. Dan juga sudah berjalan sesuai dengan perencanaan pemerintahan desa.

\section{Tata Kelola Bumdes}

BUMDes merupakan lembaga usaha desa yang pengelolaannya dikelola oleh masyarakat berserta pemerintah desa dalam upaya memerkuat perekonomian suatu desa dan dibentuk berdasarkan kebutuhan dan potensi dari desa tersebut. Melalui musyawarah desa, Pemerintah Desa berpartisipasi di dalam perkembangan pengelolaan BUMDes atas persetujuan dari Badan Permusyawaratan Desa (LPD) dan Lembaga Perwakilan Masyarakat (LPM). Hal ini dapat dilihat dari penyusunan perencanaan pembangunan desa yaitu RPJM Desa dan RKP Desa, BUMDes mendapat perhatian dengan disetujuinya beberapa program kegiatan BUMDes masuk didalam RPJM Desa dan menjadi prioritas usulan pada RKP Desa setiap tahunya yang secara otomatisakan diselenggarakan dalam APB Desa (Locus Majalan IImiah FISIP Vol. 9 No. 1 - Pebruari 2018). BUMDes Teja Kusuma ini sendiri dikelola oleh masyarakat dengan perwakilan dari pemerintah desa sebanyak 3 orang sebagai pengurus, 2 orang sebagai pengawas, dan kurang lebih 28 orang pegawai, beserta Kades desa Tejakula yang menjadi pelindung dari BUMDes Teja Kusuma. Selain itu BUMDes Teja Kusuma ini juga memiliki suatu organisasi sosial masyarakat yang dinamakan dengan Gema Cinta Jepri-Link. Dimana organisasi ini bertujuan untuk meningkatkan kesadaran dan mengajak masyarakat ikut serta dalam pengelolaan lingkungan. Contohnya seperti, pengolahan sampah organik dan non organik yang nantinya akan dijadikan sesuatu yang bernilai secara ekonomis.

\section{Penerapan prinsip akuntabilitas atau pertangggung jawaban dalam BUMDes}

Akuntabilitas adalah satu prinsip yang menjadi dasar pelaksanaan fungsi pemerintahan tidak hanya di tingkat nasional, tapi juga lokal. Pelaksanaan prinsip akuntabilitas ini sebenarnya tidak berjalan sendiri, namun dihubungkan juga dengan prinsip yang lain seperti prinsip transparansi, efektifitas dan efisiensi, partisipasi masyarakat, persamaan, responsivitas, pelaksanaan aturan hukum, konsensus bersama dan visi strategis (UNDP, 1997). Akuntabilitas dalam penyelenggaraan pemerintahan terkait dengan tanggungjawab yang dilakukan pemerintah daerah dalam melaksanakan tugas dan fungsinya; sejauh mana pemerintah daerah melaksanakan tugas dan fungsinya itu sesuai dengan kepentingan masyarakat. Ini sangat beralasan karena institusi pemerintah adalah organisasi publik yang kehadirannya terkait dengan kemunculan masyarakat. Kenyataan ini menegaskan bahwa tugas pemerintah adalah untuk melindungi bahkan menjamin hak individu warga negara secara ekonomi, sosio budaya dan politik. Inilah yang menjadi nature 
law atau prinsip moral yang menjadi dasar penyelengaraan pemerintahan yang diungkap Locke (1632- 1704).

Dalam BUMDes Teja Kusuma ini segala bentuk pengambilan keputusannya menggunakan sistem Demokrasi. Dimana dalam hal ini segala bentuk kegiatan BUMDes dilakukan dengan cara memvoting dengan suara terbanyak. Disini selaku pengurus, pengawas, beserta penanggung jawab BUMDes memiliki jumah suara sebanyak 2, dan pegawai BUMDes memiliki jumlah suara 1. Contohnya sederhananya adalah voting untuk menentukan libur hari raya. Hal ini dilakukan agar didapatkannya suatu musyawarah untuk mufakat tanpa memandang jabatan atau pengaruh dari kepengurusan di BUMDes tersebut.

Dari hasil wawancara di BUMDes Teja Kusuma, pertanggung jawaban segala kegiatan BUMDes ini dilakukan dengan cara mengadakan rapat pada musyawarah desa yang dilakukan setahun sekali pada akhir tahun. Hal yang dibahasa adalah tentang pelaporan pertanggung jawaban oleh seluruh pengurus BUMDes yang melibatkan tokohtokoh penting desa, beserta beberapa wakil dari masyarakat di desa Tejakula. Dan juga dalam rapat musyawarah desa ini juga membahas hal-hal yang belum terealisasikan oleh BUMDes. Jika terdapat kegiatan yang belum berjalan secara efektif, maka hal ini akan direalisasikan pada tahun berikutnya. Selain itu segala bentuk pengeluaran dan pemasukan yang didapatkan oleh BUMDes ini baik itu mendapat laba atau pun rugi, yang menyangkut kegiatan operasional BUMDes ini di publikasikan secara terbuka dan ditempelkan pada sisi lobi BUMDes Teja Kusuma ini. Hal ini bertujuan agar masyarakat tahu bagaimana kegiatan operasional dari BUMDes tersebut. Jadi dapat dikatakan bahwa BUMDes Teja Kusuma ini sudah menerapkan prinsip akuntabilitas atau pertanggung jawaban terhadap segala aspek kegiatan yang terjadi di dalam pelaksanaan kegiatan operasional, baik secara internal maupun eksternal.

Dibawah ini terdapat tabel pelaporan pertanggungjawaban sisa hasil usaha setiap unit usaha yang berjalan di BUMDes Teja Kusuma pada tahun 2018

1. BIAYA ADMINISTRASI DAN UMUM

\begin{tabular}{|c|c|c|c|c|}
\hline Tahun & Bulan & Pendapatan & Pengeluaran & SHU \\
\hline \multirow[t]{12}{*}{2018} & Januari & Rp. 0 & Rp 9.979.000.00 & Rp 9.979.000.00 \\
\hline & Februari & Rp. 0 & $\operatorname{Rp} 9.330 .300,00$ & Rp 9.979.000,00 \\
\hline & Maret & Rp. 0 & Rp 7.766.000,00 & Rp 7.766.000,00 \\
\hline & April & Rp. 0 & $\operatorname{Rp} 10.466 .000,00$ & Rp 10.466.000,00 \\
\hline & Mei & Rp. 0 & $\operatorname{Rp} 18.160 .000,00$ & $\mathrm{Rp} 18.160 .000,00$ \\
\hline & Juni & Rp. 0 & Rp 8.318.000,00 & Rp 8.318.000,00 \\
\hline & Juli & Rp. 0 & Rp 7.074.000,00 & Rp 7.074.000,00 \\
\hline & Agustus & Rp. 0 & Rp 8.429.000,00 & Rp 8.429.000,00 \\
\hline & September & Rp. 0 & Rp 9.004.000,00 & Rp 9.004.000,00 \\
\hline & Oktober & Rp. 0 & $\operatorname{Rp} 16.186 .000,00$ & $\operatorname{Rp} 16.186 .000,00$ \\
\hline & November & Rp. - & $R p-$ & $R p-$ \\
\hline & Desember & Rp. - & $\mathrm{Rp}-$ & $\mathrm{Rp}-$ \\
\hline
\end{tabular}

2. UNIT USAHA DAGANG / TOKO

\begin{tabular}{|c|c|c|c|c|}
\hline Tahun & Bulan & Pendapatan & Pengeluaran & SHU \\
\hline \multirow{10}{*}{2018} & Januari & Rp 1.193.000,00 & Rp 1.193.000,00 & $\operatorname{Rp} 0$ \\
\hline & Februari & $\operatorname{Rp} 0$ & $\operatorname{Rp} 0$ & Rp 0 \\
\hline & Maret & $\mathrm{Rp} 0$ & $\mathrm{Rp} 0$ & $\operatorname{Rp} 0$ \\
\hline & April & $\operatorname{Rp} 11.193 .000,00$ & $\operatorname{Rp} 11.193 .000,00$ & Rp 0 \\
\hline & Mei & Rp 0 & Rp 0 & Rp 0 \\
\hline & Juni & Rp 0 & Rp 0 & Rp 0 \\
\hline & Juli & Rp 0 & Rp 0 & Rp 0 \\
\hline & Agustus & $\operatorname{Rp} 0$ & $\operatorname{Rp} 0$ & Rp 0 \\
\hline & September & Rp 0 & Rp 0 & Rp 0 \\
\hline & Oktober & $\operatorname{Rp} 57.000,00$ & Rp 559.000,00 & Rp 13.000,00 \\
\hline
\end{tabular}




$\begin{array}{llll}\text { November } & R p- & R p- & R p- \\ \text { Desember } & R p- & R p- & R p-\end{array}$

\section{UNIT USAHA SIMPAN PINJAM}

\begin{tabular}{|c|c|c|c|c|}
\hline Tahun & Bulan & Pendapatan & Pengeluaran & SHU \\
\hline \multirow[t]{12}{*}{2018} & Januari & Rp 9.839.833,00 & Rp 1.830.000,00 & Rp 8.009.883,00 \\
\hline & Februari & Rp 2.940.373,00 & $\operatorname{Rp} 1.830 .000,00$ & $\operatorname{Rp} 1.110 .373,00$ \\
\hline & Maret & Rp 6.002.264,00 & $\operatorname{Rp} 1.905 .000,00$ & $\operatorname{Rp} 4.097 .264,00$ \\
\hline & April & Rp1.642.296,00 & $\operatorname{Rp} 2.430 .000,00$ & $\operatorname{Rp} 787.704,00$ \\
\hline & Mei & $\operatorname{Rp} 1.985 .506,00$ & $\operatorname{Rp} 1.830 .000,00$ & $\operatorname{Rp} 155.506,00$ \\
\hline & Juni & $\operatorname{Rp} 1.390 .587,00$ & $\operatorname{Rp} 1.830 .000,00$ & $\operatorname{Rp} 439.413,00$ \\
\hline & Juli & $\operatorname{Rp} 2.085 .521,00$ & $\operatorname{Rp} 1.830 .000,00$ & $\operatorname{Rp} 255.521,00$ \\
\hline & Agustus & $\operatorname{Rp} 1.412 .612,00$ & $\operatorname{Rp} 1.830 .000,00$ & $\operatorname{Rp} 417.388,00$ \\
\hline & September & $\operatorname{Rp} 7.827 .509,00$ & $\operatorname{Rp} 2.430 .000,00$ & Rp 5.397.509 \\
\hline & Oktober & Rp 2.091.905,00 & Rp1.830.000,00 & $261.905,00$ \\
\hline & November & $\mathrm{Rp}-$ & $\mathrm{Rp}-$ & $\mathrm{Rp}-$ \\
\hline & Desember & Rp - & $\mathrm{Rp}$ & $\mathrm{Rp}-$ \\
\hline
\end{tabular}

4. UNIT USAHA PENGELOLAAN SAMPAH

\begin{tabular}{|c|c|c|c|c|}
\hline Tahun & Bulan & Pendapatan & Pengeluaran & SHU \\
\hline \multirow[t]{12}{*}{2018} & Januari & $\mathrm{Rp} 38.528 .702,00$ & Rp 29.816.896,00 & Rp 8.711.806,00 \\
\hline & Februari & Rp 24.921.413,00 & Rp 26.127.846,00 & Rp 1.206.433,00 \\
\hline & Maret & Rp 14.824.599,00 & Rp 20.262.077,00 & Rp 5.437.478,00 \\
\hline & April & Rp $10.027 .022,00$ & Rp 25.714.272,00 & $\mathrm{Rp}-15.642 .272$ \\
\hline & Mei & Rp 15.253.000,00 & Rp 38.539.307,00 & Rp 23.286.307 \\
\hline & Juni & Rp 15.117.000,00 & Rp 46.368.307,00 & Rp 31.251.307,00 \\
\hline & Juli & Rp 52.954.000,00 & Rp 56.709.207,00 & Rp 3.755.027,00 \\
\hline & Agustus & Rp 12.596.000,00 & Rp 25.037.707,00 & Rp 12.441.707,00 \\
\hline & September & Rp 16.060.000,00 & Rp 37.996.707,00 & Rp 21.936.707,00 \\
\hline & Oktober & Rp 52.484.364,00 & Rp 54.016.707,00 & Rp $1.532 .707,00$ \\
\hline & November & Rp 39.572.000,00 & Rp 27.620.343,00 & Rp 11.951.657,00 \\
\hline & Desember & $\mathrm{Rp}$ - & $\mathrm{Rp}$ - & $\mathrm{Rp}-$ \\
\hline
\end{tabular}

5. UNIT USAHA JASA PELAYANAN SAMSAT

\begin{tabular}{|c|c|c|c|c|}
\hline Tahun & Bulan & Pendapatan & Pengeluaran & SHU \\
\hline \multirow[t]{12}{*}{2018} & Januari & Rp 860.000,00 & Rp 460.000,00 & $\operatorname{Rp} 400.000,00$ \\
\hline & Februari & $\mathrm{Rp} 740.000,00$ & $\operatorname{Rp} 380.000,00$ & $\mathrm{Rp} 360.000,00$ \\
\hline & Maret & $\mathrm{Rp} 810.000,00$ & $\mathrm{Rp} 430.000,00$ & $\mathrm{Rp} 380.000,00$ \\
\hline & April & $\mathrm{Rp} 870.000,00$ & $\mathrm{Rp} 460.000,00$ & $\operatorname{Rp} 410.000,00$ \\
\hline & Mei & $\mathrm{Rp} 830.000,00$ & $\mathrm{Rp} 440.000,00$ & Rp $390.000,00$ \\
\hline & Juni & $\mathrm{Rp} 460.000,00$ & $\mathrm{Rp} 240.000,00$ & Rp 220.000,00 \\
\hline & Juli & $\mathrm{Rp} 680.000,00$ & $\operatorname{Rp} 360.000,00$ & Rp $320.000,00$ \\
\hline & Agustus & $\mathrm{Rp} 360.000,00$ & Rp $190.000,00$ & Rp $170.000,00$ \\
\hline & September & $\operatorname{Rp} 950.000,00$ & $\operatorname{Rp} 500.000,00$ & $\mathrm{Rp} 450.000,00$ \\
\hline & Oktober & $\mathrm{Rp}$ - & $\mathrm{Rp}$ - & $\mathrm{Rp}$ - \\
\hline & November & $\mathrm{Rp}-$ & $\mathrm{Rp}-$ & $\mathrm{Rp}-$ \\
\hline & Desember & $R p-$ & $R p-$ & $R p-$ \\
\hline
\end{tabular}




\section{UNIT USAHA PENGELOLAAN PASAR}

\begin{tabular}{|c|c|c|c|c|}
\hline Tahun & Bulan & Pendapatan & Pengeluaran & SHU \\
\hline \multirow[t]{12}{*}{2018} & Januari & $\operatorname{Rp} 8.167 .000,00$ & $\operatorname{Rp} 3.762 .000,00$ & $\operatorname{Rp} 4.494 .600,00$ \\
\hline & Februari & Rp 8.354.000,00 & Rp 3.897.000,00 & $\operatorname{Rp} 4.456 .450,00$ \\
\hline & Maret & Rp 7.768.000,00 & Rp 3.899.000,00 & Rp 3.869.000,00 \\
\hline & April & Rp 8.354.000,00 & Rp 3.897.550,00 & $\operatorname{Rp} 4.456 .450,00$ \\
\hline & Mei & Rp 7.768.500,00 & $\operatorname{Rp} 3.415 .400,00$ & $\operatorname{Rp} 4.353 .100,00$ \\
\hline & Juni & Rp 7.516.000,00 & $\operatorname{Rp} 6.493 .750,00$ & $\operatorname{Rp} 1.002 .250,00$ \\
\hline & Juli & Rp 7.492.000,00 & $\operatorname{Rp} 4.318 .000,00$ & Rp 3.173.500,00 \\
\hline & Agustus & Rp 7.223.500,00 & Rp 3.436.000,00 & Rp 3.787.500,00 \\
\hline & September & Rp 7.064.500,00 & Rp 4.917.000,00 & Rp 2.145.500,00 \\
\hline & Oktober & Rp 7.154.500,00 & Rp 3.171.000,00 & Rp 3.983.500,00 \\
\hline & November & Rp - & $\mathrm{Rp}-$ & $\mathrm{Rp}-$ \\
\hline & Desember & $R p-$ & $R p-$ & Rp - \\
\hline
\end{tabular}

7. UNIT USAHA JASA PELAYANAN AIR MINUM ( JPAM )

\begin{tabular}{|c|c|c|c|c|}
\hline Tahun & Bulan & Pendapatan & Pengeluaran & SHU \\
\hline \multirow[t]{12}{*}{2018} & Januari & $\operatorname{Rp} 51.245 .200,00$ & Rp 24.768.500,00 & $\operatorname{Rp} 26.476 .700,00$ \\
\hline & Februari & Rp 37.269.000,00 & Rp 21.014.000,00 & Rp 16.255.000,00 \\
\hline & Maret & Rp 30.534.300,00 & Rp 19.170.300,00 & Rp 11.364.300,00 \\
\hline & April & Rp 32.872.300,00 & Rp 22.947.000,00 & Rp 9.925.300,00 \\
\hline & Mei & Rp 40.677.800,00 & Rp 21.233.500,00 & Rp 19.444.300,00 \\
\hline & Juni & $\operatorname{Rp} 46.231 .100,00$ & Rp 25.827.000,00 & $\operatorname{Rp} 20.404 .100,00$ \\
\hline & Juli & $\operatorname{Rp} 50.467 .700,00$ & Rp 28.077.000,00 & Rp 22.390.700,00 \\
\hline & Agustus & $\operatorname{Rp} 46.944 .100,00$ & Rp 24.240.500,00 & $\operatorname{Rp} 22.703 .600,00$ \\
\hline & September & $\operatorname{Rp} 52.260 .700,00$ & Rp 31.142.400,00 & $\operatorname{Rp} 21.008 .300,00$ \\
\hline & Oktober & $\operatorname{Rp} 50.930 .100,00$ & Rp 26.384.100,00 & Rp 24.546.000,00 \\
\hline & November & $\mathrm{Rp}-$ & Rp - & Rp - \\
\hline & Desember & $\mathrm{Rp}-$ & Rp - & $\mathrm{Rp}-$ \\
\hline
\end{tabular}

\section{Simpulan dan Saran Simpulan.}

Menurut Undang Undang Nomor 5 Tahun 1979 menyatakan bahwa "Desa adalah suatu wilayah yang ditempati oleh sejumlah penduduk sebagai kesatuan masyarakat termasuk didalamnya kesatuan masyarakat hukum yang mempunyai organisasi pemerintahan terendah langsung dibawah camat dan berhak menyelenggarakan rumah tangganya sendiri dalam ikatan kesatuan Republik Indonesia.

Dalam lingkup desa perlu terdapat sumber-sumber pendanaan desa seperti pendapatan asli desa, pendapatan asli desa ini berasal dari usaha hasil BUMdes. Dalam UU No. 6 tahun 2014 dijelaskan bahwa BUMdes merupakan badan usaha yang seluruh atau sebagian modalnya dimiliki oleh desa melalui penyertaan secara langsung yang berasal dari kekayaan desa yang dipisahkan guna mengelola aset,jasa pelayanan,dan usaha lainya untuk sebesar-besarnya kesejahteraan masyarakat desa.

Akuntabilitas merupakan istilah yang digunakan untuk menggambarkan tingkat pertanggungjawaban seseorang ataupun suatu lembaga tertentu yang berkaitan dengan sistem administrasi yang dimilikinya.Akuntabilitas dalam penyelenggaraan pemerintahan terkait dengan tanggungjawab yang dilakukan pemerintah daerah dalam melaksanakan tugas dan fungsinya.

Dalam BUMDes Teja Kusuma ini segala bentuk pengambilan keputusannya menggunakan sistem Demokrasi.Disini selaku pengurus, pengawas, beserta penanggung jawab BUMDes memiliki jumah suara sebanyak 2, dan pegawai BUMDes memiliki jumlah suara 1.Hal yang dibahasa adalah tentang pelaporan pertanggung jawaban oleh seluruh 
pengurus BUMDes yang melibatkan tokoh-tokoh penting desa, beserta beberapa wakil dari masyarakat di desa Tejakula.

Jadi dapat dikatakan bahwa BUMDes Teja Kusuma ini sudah menerapkan prinsip akuntabilitas atau pertanggung jawaban terhadap segala aspek kegiatan yang terjadi di dalam pelaksanaan kegiatan operasional, baik secara internal maupun eksternal.

\section{Saran.}

Berdasarkan kesimpulan yang ada diatas, agar partisipasi masyarakat terhadap program bumdes dapat meningkat lagi, maka peneliti memberikan saran sebagai berikut:

1. bumdes desa tejakula sebaiknya mengadakan sosialisasi secara menyeluruh kepada masyarakat desa tejakula agar masyarakat dapat memahami banyaknya manfaat yang dapat diperoleh dari keikutsertaan terhadap program program yang ada di desa tejakula .

2. Masyarakat desa tejakula seharusnya lebih meningkatkan kesadaran berpartisipasi terhadap program bumdes untuk meningkatan kesejahteraan bersama.dan kesejahteraan masyarakat danikut serta dalam usaha yang dijalankan di bumdes.

3. Bagi masyarakat di desa tejakula diharapkan dapat memahami dan mengerti tentang program pemerintah desa untuk membentuk bumdes demi kemajuan dan perkembangan desa serta dapat meningkatkan taraf prekonomian

\section{DAFTAR PUSTAKA}

Coryanata, Isma. 2012. AKUNTABILITAS, PARTISIPASI MASYARAKAT DAN TRANSPARANSI KEBIJAKAN PUBLIK SEBAGAI PEMODERASI HUBUNGAN PENGETAHUAN DEWAN TENTANG ANGGARAN DAN PENGAWASAN KEUANGAN DAERAH. Jurnal Akuntansi dan Investasi Vol. 12 No. 2, halaman: 110-125.

Dian, Ahmad. 2016. Badan Usaha Milik Desa Ciri-ciri, Tujuan, Landasan Hukum, Dan Jenis Usaha. https://www.google.co.id/amp/s/dosenekonomi.com/ilmu-ekonomi/bumn/badanusaha-milik-desa/amp.Diakses pada 6 Januari 2019.

Sande, Peggy. 2013. PENGARUH PENYAJIAN LAPORAN KEUANGAN DAN AKSESIBILITAS LAPORAN KEUANGAN TERHADAP AKUNTABILITAS PENGELOLAAN KEUANGAN DAERAH (Studi Empiris Pada Pemerintah Provinsi Sumatera Barat). Universitas Negeri Padang.

Sadjiarto, Arja. 2000. AKUNTABILITAS DAN PENGUKURAN KINERJA PEMERINTAHAN. Jurnal Akuntansi dan Keuangan Vol. 2, No. 2, Nopember 2000:138-150. 